\title{
Research of brain drain problem of small and medium-sized civil airport in northeast China
}

\author{
Lin $\mathrm{Yu}$ \\ Department of Economic Management,Shanghaixingjian Business College , Yuanping Road \\ 55,Jingan District , Shanghai ,China \\ yulin0526@163.com
}

Key words: civil airport. state-owned enterprises. brain drain. people-oriented

\begin{abstract}
Talents are the source of continuous development of enterprises, and strengthening human resource management is the guarantee of improving the competitive advantage of enterprises. According to the characteristics of the civil airport in northeast China, this paper analyses the current civil airport in northeast China and the causes of brain drain, and put forward to strengthen the management of the brain drain of small and medium-sized state-owned civil airport countermeasure analysis.
\end{abstract}

\section{Mistake of Human Resource Management in the Small and Medium-sized Civil Aviation Airport in Northeast China}

\subsection{Lack of humanistic management}

$\mathrm{ABC}$ civil airport in northeast in the enterprise operation process, there is no "human resources management, human capital management, people-oriented" concept of human resource management still stays on the level of personnel management, emphasis on individual to obey the distribution, denied individual needs and personality. Think of a person as a cost investment. Personnel management is only the simple management of the talent, the pipe out, the potential that does not fully develop the person. On the strategic point of view, the management of enterprise human resources is lacking in general and long-term. In the form of management is static management; It is traditional and rigid in the way of management; The lack of scientific and artistic skills in management techniques; Old and backward in the means of management; In the management system, it is only passive aftermanagement.

\subsection{There is no effective level playing field}

Start with interpersonal relationships in your daily work, rather than work needs and business interests. There is a lack of objectivity, centralization, dislocation of halo and personal bias in performance appraisal, promotion, title evaluation and job change. "Dry and bad is the same thing, do not do the same thing", the phenomenon of the redundancy seriously frustrate the enterprise of some excellent people. In the enterprise of factional phenomenon, "the va cadres" and "academic", by 2004, ABC airport is a boss of three pairs of all cadres, the va nearly more than 15 at the cadre only 2 people are college graduates. This is an abnormal phenomenon, and the phenomenon of the outside line is seriously hindering the development of the enterprise. The lack of fair competition is one of the main causes of brain drain.

\subsection{Lack of effective pay managemen}

In the northeast, the sector is relatively low relative to wages in the north and southeast coasts. According to maslow's hierarchy theory, the company's wages can only meet the needs of subsistence 
and safety, not meet the high level of spiritual needs. Those who want to stay can't stay, and those who don't want to stay are often full. There is a common phenomenon in the enterprise that there is less to do than to do. The serious lack of reward has killed the innovative spirit and the enthusiasm of the enterprise. The combination of internal exclusion and external attractiveness increases the pool of talent.

1.4 The negative effect of the enterprise's bad behavior on the psychological factors of the talent.

The sense of belonging and respect for talent is not met. When they are not recognized by organizations, and all of their work lose enthusiasm, muddle along, work attitude every step, resentful of unreasonable phenomenon. Is the most important performance, in the formal organization and informal organization midstream shows his discontent, although work as usual, but attention on complaints, mistrust of leadership, talent for managers lose confidence, serious backlash, rebellious attitude, using various occasion to criticize the existing system is not reasonable, open conflict with the manager. The loss of confidence in the development of the enterprise and the distance between companies and leaders in psychology has accelerated the process of leaving the workforce.

\subsection{Professional and versatile}

For example, the pilot, security personnel, conductor, check-in staff, their professional requirement is very high, once left the industry, their professional technology lose comes in. So some people began to talk, not as good as young learn other professional technology, such as to take an examination of CPA license, a license, go to graduate school, etc., and have the idea of the departure.

\subsection{The appraisal system is not sound enough}

It is not scientific and reasonable to establish the criterion of evaluation and evaluation, and the performance appraisal is not combined with the employee's performance. In civil aviation enterprises to do the assessment results various purposes, usually an assessment event of exposure, the higher the frequency, director of the greater the pressure, also more. The director is based on these concerns and does not want to actually implement the appraisal. Cause some performance appraisal through the motions, and become a mere formality, advanced became "rotation", so that the final forming supervisor didn't want to take an examination of, employees don't want to be, human resource managers also not interested organizations take an examination of the situation.

\section{Reasons for the Misunderstanding are Analyzed}

The problem of human resource management in the small and medium-sized civil airport in the northeast is the cause of its long history and the reason for its reality. Main is:

1, "born" in the planned economy the old state-owned enterprise, its organization setup and personnel arrangement mechanism lead to the business enterprise inside wood is numerous, is one of the main reasons for low efficiency of enterprises. The enterprise of the plan economy is "boss" enterprise, all sorts of people try to find a way to squeeze into this "boss". With the increasing number of people, labor productivity is falling, and people are becoming a common phenomenon in enterprises. Therefore, the "dead man" has become the biggest obstacle to the organization of civil aviation enterprises, affecting the production and development of enterprises.

2.The wages, bonuses and benefits of the small and medium-sized civil airport workers in the northeast are still largely inherited from the planned economy. Linked to the performance of the worker income, is still in a "low income difference rate" doing more less the same, the technical quality of the same state of "pot". This kind of stimulation method is weak, add the mechanism of choose and employ persons not to live, it is serious frustrate the worker of the enterprise the enthusiasm of the 
work and create enthusiasm important reason.

3.Small and medium-sized civil airport in northeast China in the process of operation, because on business philosophy can not adapt to market economy and the constant change, at the same time, influenced by the civil aviation enterprises, the adjustment of structural, etc. "Low income inequality" inevitably leads to a lack of talent and severe brain drain, which can't be effectively changed and contained.

4.At present, the shortage of human resources is prevalent in the small and medium-sized civil airports in the northeast. The enterprises that are profitable, though they have some financial resources, are afraid to invest in human resources on a large scale. Enterprises, poor profit and no resources to invest in human resource construction, and makes the enterprise worker in age, knowledge, technology, structure of aging and scraping is widespread on the imbalance of human resources present situation, really has the modern knowledge and technical personnel, who understand modern management personnel are scarce.

5.The organization structure of enterprise human resources are mostly carry on the management of the planned economy mode, the administrative personnel management atmosphere, is brought about by the "people-oriented", "to help" consciousness indifference. The "pyramid" structure limits corporate information communication and scientific decisions. Division is the content of human resource management, make the resource acquisition, use, communicate individually, each other, such as investment, motivation, and make the enterprise human resources planning strategy and enterprise development to internal integration, failed to reflect insufficiency, the unity of human resources management.

\section{Countermeasure analysis of retaining talent}

1.The first resource is the management idea of the first resource

Along with the arrival of information age, people get an unprecedented increase, human capital has surpassed the material capital and monetary capital become one of the main factors of production and an important part of social wealth. There must be a new perspective on the role and value of the enterprise's talent. The competition of knowledge, the competition of information, the competition of the rate of reaction, is the competition of talents. The key is to compete for human-centered management ideas. Companies need to create a system that keeps finding talent, developing talent, and doing it well. Let the candidates. We will provide more freedom and broader development space for the talented people.

2.We will improve the mechanism for selecting the best and the fittest and fair competition

In order to attract talents and retain talented people, state-owned enterprises should solve the problems of seniority, cronyism and accommodation. We will establish a fair, fair and open competition for employers. "The promising talents, recruiting, to attract the best talent to the enterprise, outstanding talent is found in its unique personality, and full of charm of creative talents is the most valuable capital enterprise, make the enterprise the source of new development. To recognize the characteristics of talents so that they can show and exert their talents and creative potential in a unique development.

3.We will improve the compensation system, the welfare system, and establish a long-term mechanism for personnel incentives

According to the behavioral scientists proposed by Adams fair theory, people not only care about their absolute returns, are also concerned about themselves and others in the work and pay the relative 
relations, namely people for their input and output of compared with others within the organization, only think equal justice. Otherwise, there will be a "fair and tense" phenomenon, which will affect future efforts. Allow the compensation system to really reflect the employee's contribution. Implement comprehensive salary strategy, especially in and internal compensation, external compensation mainly refers to the monetary value of employees to provide quantifiable, internal compensation worth is provided to employees can't indicate in quantitative value of awards. Companies provide convenience for the talent of computer tools, training opportunities, a chance to improve your personal reputation, create a good environment and interpersonal relationship together working environment. Internal and external compensation have different incentive function, contact and cooperate with each other, each other to form a complete system, the enterprise personnel form popular incentive ${ }^{[1]}$.

4.Scientific design salary, build incentive and performance appraisal mode

Civil aviation enterprises tend to allocate the distribution according to law, efficiency and resources. Distribution system should be centered on enterprise benefits, the staff's responsibility, right and benefit together, increase the salary structure of "living wage" proportion, open distribution class. Fundamentally exist in the process of solving the distribution of worker pay and labor market, wage levels do not reflect the problem such as difference of labor, breaking the egalitarianism formation in the compensation reform, realize the contribution mostly, small contribute little ${ }^{[2]}$.

Civil aviation enterprises should establish a multi-level, multidimensional, multi-method integrated system for human resources evaluation. Performance evaluation from the direct supervisor, colleagues, subordinates, customers and was evaluators individuals such as 360 - degree Angle, evaluation content includes work quantity, quality, time, cost, etc. In specific implementation process, first must carry on the work analysis, established practical and feasible performance evaluation index system, rules, and then USES the scientific and reasonable evaluation method to measure the actual performance and dynamic feedback in order to constantly revise. In order to make the performance evaluation of comparable between various kinds of jobs that can be applied to performance index method to reflect the change of external environment of various technical conditions, the adjustment of the macro policy and the change of organizational system, personnel system and other uncertain and uncontrollable factors influence on job performance, to make evaluation results more objective and fair, and combined with the corresponding incentive measures, promote the organization or individual efforts to create a higher performance, so as to successfully achieve the strategic goals of the enterprise ${ }^{[3]}$.

\section{Conclusion}

To sum up, the small and medium-sized civil airport in northeast China are relatively serious brain drain, enterprise managers must carefully analyze their own human resources management present situation and reasons of backward, full awareness of the need for change behind human resource management, find the suitable for their own characteristic way of human resource management ${ }^{[4]}$. Should pay attention to talent selection, hiring, training, management process, shaped by culture, environmental regulation and benefit drive, is to provide diversified and challenging tasks and the opportunity to participate in the management, to create a knowledge of the environment for people to make personnel feel incentives also aware of the coming of the challenge, motivate employees to constantly learning and constantly update the knowledge structure of desire. Cultivate employees' sense of loyalty to the organization and minimize the risk of brain drain. Finally, we must fully recognize the scarcity and irreplaceability of key talents. The competition of future enterprises is the competition of talents, combined with their own characteristics, the strategy of coping with the loss of talents is suitable for enterprises ${ }^{[5]}$. 


\section{References}

[1] Satoshi Kagami,Tomonobu Kitagawa,Koichi Nishiwaki,Tomomichi Sugihara,Masayuki Inaba,Hirochika Inoue. A Fast Dynamically Equilibrated Walking Trajectory Generation Method of Humanoid Robot [J], 2002.

[2] HIROKIK, MINORUA, YASUOK, ET al.RoboCup: a challenge problem for AI and robotics. HirokiK. RoboCup-97: Robot Soccer World Cup [C]. Berlin: Springer, 1998.38-43.

[3] Zhizhong Yin. Application of FPGA control DC motor servo system [J]. Inner Mongolia Science and Technology and Economy, 2008177 (23) 101-103.

[4] Joerg Christian Wolf, Phil Hall, Paul Robinson, Phil Culverhouse. Bioloid based Humanoid Soccer Robot Design, 2007.

[5] Wu Chuan-yu, He Lei-ying, Design and Realization of Instructional RPPR-Robot, Research and Exploration in Laboratory.2007, 26(10) 